\title{
Alemania, año cero: orígenes ordoliberales de la Unión Europea y nuevo constitucionalismo disciplinario ${ }^{1}$
}

\author{
Germany, year zero: ordoliberal origins of the European \\ Union and new disciplinary constitutionalism
}

ALEJANDRO SÁNCHEZ BERROCAL (Instituto de Filosofía del CSIC)

Artículo recibido: 2 de junio de 2020

Solicitud de revisión: 28 de julio de 2020

Artículo aceptado: 3 de agosto de 2020

Sánchez Berrocal, Alejandro (2020). Alemania, año cero: orígenes ordoliberales de la Unión Europea y nuevo constitucionalismo disciplinario. Recerca. Revista de Pensament $i$ Análisi, $25(2), 95^{-115}$.

\section{Resumen}

Este artículo reconstruye algunas líneas fundamentales que componen el programa filosófico-político del ordoliberalismo y su impacto en el proceso de integración europea. En él, se analizan las consecuencias éticas y políticas de las ideas ordoliberales relativas al papel del Estado y la función del mercado a través de sus figuras y nociones claves. Además, se elabora un diagnóstico de la matriz ordoliberal que inspira la política de la Unión Europea desde la perspectiva de un nuevo constitucionalismo disciplinario cuyo objetivo es desvincular las políticas nacionales del control democrático y social mediante su atribución a marcos jurídicos de carácter supranacionales.

Palabras clave: ordoliberalismo, estado, nuevo constitucionalismo, Unión Europea, soberanía.

\section{Abstract}

This article reconstructs some of the fundamental lines that constitute the philosophicalpolitical program of ordoliberalism and its impact on the process of European integration. In this article, the ethical and political consequences of ordoliberal ideas regarding the role of

\footnotetext{
Esta investigación es posible gracias a un contrato FPU (17/03632) del Ministerio de Educación, Cultura y Deporte y se enmarca en las actividades del proyecto PAIDESOC (FFI2017-82535-P) «El desván de la razón: Cultivo de las pasiones, identidades éticas y sociedades digitales», cuya investigadora principal es Concha Roldán Panadero (IFS-CSIC).
} 
the State and the function of the market are analyzed through its key representatives and notions. In addition, a diagnosis of the ordoliberal matrix that inspires the policy of the European Union is elaborated from the perspective of a new disciplinary constitutionalism whose objective is to free national policies from democratic and social control through their attribution to supranational legal frameworks.

Key Words: Ordoliberalism, State, New constitutionalism, European Union, Sovereignty.

\section{INTRODUCCIÓN}

Existe una popular fotografía, tomada en un centro estadounidense de prisioneros de guerra poco después de concluir la segunda guerra mundial, donde se retrata una improvisada sala de cine abarrotada de soldados alemanes a los que se les muestran imágenes de los campos de concentración nazis. Las reacciones son muy variadas y expresan sentimientos encontrados: algunos miran a la pantalla con indiferencia, rabia o resignación, quizás creyendo que es mera propaganda norteamericana; otros se tapan la cara con las manos, incapaces de ver el horror del que han sido cómplices, quién sabe si pensando si su nación ha sido capaz de formar parte de esos crímenes. Se ha llegado a decir incluso que, después de ver tales imágenes, algunos soldados quemaron sus uniformes nazis y se dedicaron a hacer colectas para los supervivientes del Holocausto (Thompson, 2010:119). La instantánea puede funcionar como metáfora de una nación que, tras el horror del nazismo, ha sufrido un shock tal en su memoria colectiva que le impide afrontar el pasado reciente. El olvido alcanzará dimensiones explícitamente filosóficas, cuya expresión más evidente es la ausencia de crítica -o al menos de reflexión - que se le atribuye a Martin Heidegger: «iPuede interpretarse también el asesinato planificado de millones de hombres, del que hoy ya no ignoramos nada, como un error que nos fue deparado como un destino en el contexto de la historia del Ser?», se preguntaba un joven Habermas (1975: 64). Algunos años antes de genocidas olvidos del ser, se venía fraguando la solución para una Alemania en ruinas que no tardó en resurgir de sus cenizas pagando el precio de un trauma: el olvido de su historia, la redefinición de su relación con la memoria colectiva y el establecimiento de un nuevo tipo de temporalidad:

La ruptura con la historia puede ser percibida y aceptada como una ruptura con la memoria, en la medida en que va a instaurarse en Alemania una nueva dimensión de la temporalidad que no es tanto la propia de la historia, sino que será una creencia económica [...] La libertad económica coproducida por la creencia y el buen hacer del Estado y el olvido de 
la historia [...] Encontramos, en la Alemania contemporánea, un Estado que podemos denominar radicalmente económico, considerando «radicalmente» en sentido estricto del término, pues su raíz es estrictamente económica (Foucault, 2004: 87). ${ }^{2}$

Pues bien, Alemania, año cero, ya que no son la historia ni la política los dominios que de ahora en adelante van a aportarle su razón de ser, sino que el pilar de la nueva nación consistirá en la racionalidad económica convertida en fuente de derecho, legitimidad y consenso político. Esta percepción es tributaria de la variante neoliberal alemana, el ordoliberalismo (Ordoliberalismus). El ordoliberalismo es una corriente de pensamiento económico y político que fue madurando en los años 1930 alrededor de un núcleo duro, la llamada escuela de Friburgo, con figuras como el economista Walter Eucken o los juristas Franz Böhm y Hans Grossman-Doerth, y a la que también contribuyeron otros intelectuales ajenos a la escuela, siendo los más conocidos Alfred Müller-Armack, Wilhelm Röpke y Alexander Rüstow. Tras el horror del nazismo, este grupo de intelectuales pretende buscar una tercera vía que no consista en el liberalismo clásico vinculado al laissez-faire ni en la planificación estatal ligada al socialismo, de ahí que propugnen el ordoliberalismo, literalmente un 'liberalismo ordenado'. De acuerdo con la reconstrucción de la crítica ordoliberal al nazismo que elaboran Laval y Dardot (2013: 105), desde la perspectiva de estos economistas, la experiencia nazi no tuvo nada de anómalo, sino que fue la «conclusión natural y la verdad de la economía planificada y dirigida», economía que Wilhelm Röpke llega a denominar «de comando» (Kommandowirtschaft) y Walter Eucken bajo el rótulo «economía administrada centralizadamente» (Zentralverwaltungsirstschaft). La idea clave pasa por diagnosticar como verdadero culpable de la atomización social y la disolución comunitaria al dirigismo y planificación económicos en cuanto instrumentos de un Estado fuerte.

En este artículo nos proponemos desarrollar las principales ideas éticas, políticas y económicas que componen el ideario ordoliberal, así como dar cuenta de la influencia que este ha tenido en el proceso de integración europea. Nos preguntamos si la constitución económica y social que de facto ha asumido la UE (neomercantilismo alemán, mezzogiornificazione del sur de Europa, políticas de austeridad) es una de las causas que, especialmente desde la crisis de la eurozona del 2010, está detrás del proceso de desvinculación de las políticas nacionales del control democrático y social mediante su atribución a marcos jurídicos transnacionales.

2 En todo el artículo, la traducción de citas en idiomas extranjeros es propia. 
El recorrido argumental comienza con una explicación del contexto histórico y social en que surge el ordoliberalismo y sus principales referentes intelectuales, lo que permitirá comprender algunos de los principales temas ordoliberales: necesidad de pacificación social, desconfianza en el Estado y necesidad, incluso, de un autoritarismo capaz de asegurar el orden social. Para profundizar en la esencia del ordoliberalismo, repasamos sus conceptos fundamentales. Por último, abordamos el problema de la integración europea desde el enfoque del nuevo constitucionalismo como la forma específica que adquiere el neoliberalismo disciplinario en el interior de la UE.

\section{DECLINACIÓN DEL ESTADO, AUTORITARISMO Y PACIFICACIÓN SOCIAL}

De la misma manera que los neoliberales, las principales mentes detrás del ordoliberalismo creen que el colapso de los sistemas democráticos en Europa después de las dos guerras mundiales es el resultado de una violación del libre mercado por las políticas estatales de carácter totalitario, lo que aportará el barniz ideológico necesario para que el Estado se repliegue. Incluso ya en la década de los años treina, Alexander Rüstow (2017 [1932]: 143) afirmaba que «la crisis actual de Alemania ha sido causada en gran parte por políticas de intervencionismo y subsidios estatales». Quien recoge de modo explícito esta opinión es Walter Eucken (1932: 306) al señalar cómo tras la secularización religiosa ha quedado un vacío que el ser humano necesita remplazar para dar sentido a su vida, a saber, el Estado: «hoy día el Estado se ha convertido en un sustituto de la religión, y se trata de una creencia en su total y todopoderoso poder». Semejante nueva fe sería una tradición especialmente arraigada en el pueblo germánico: «muchos alemanes ven en el estado total el futuro de una entidad sobrehumana capaz de todo, en relación a la cual el individuo no posee ningún derecho». Según las conclusiones de Eucken (1932: 318), Alemania ha aprendido «que cualquier intento de intervención por parte del estado creará disrupciones indeseables», por lo que es recomendable que el Estado «se libere a sí mismo del poder de las masas y se distancie de algún modo de la economía». A propósito de los intelectuales de su tiempo, Eucken (1932: 320) se lamenta de que «no sean capaces de ver cómo el intervencionismo transforma una economía ordenada en caos».

Otra expresión de las reconfiguraciones ideológicas a propósito del papel del Estado podemos encontrarla en el pensamiento de Ludwig Erhard, padre del 
llamado milagro económico alemán, con la difusión del concepto de sociedad formada o integrada (Formierte Gesellschaft) y la noción de economía social de mercado (Soziale Marktwirtschaft). La idea de sociedad formada hace referencia a la Alemania de posguerra - para ser exactos, la República Federal de Alemania- como una sociedad que no se habría formado entre clases y grupos que persiguen objetivos excluyentes, sino que van en la misma dirección guiados por el interés general. Esta concepción presupone dos objetivos: la pacificación de los conflictos de clase y la integración de la sociedad en el mecanismo de competencia y el régimen de propiedad. Con el fin de evitar el predominio de los temidos intereses parciales (fórmula para designar al movimiento sindical y la presión de las clases subalternas por mejores condiciones económicas), la solución pasa por hacer de la economía fuente de legitimidad, mecanismo paradigmático de funcionamiento social y ratio última de lo político. Con este entusiasmo hablaba Erhard (1982 [1965]: 64) del modelo alemán: «el magnetismo de la sociedad integrada se demostrará superior al resto de modelos sociales. Tanto ideológica como políticamente, erosionará el socialismo». Aparece el verdadero enemigo - el socialismo-, que sirve para demonizar al Estado, porque «una sociedad integrada no puede ser dictada por el Estado» (Erhard, 1982 [1965]: 64).

Esto nos pone frente a la verdadera naturaleza de las reflexiones de Erhard: utilizar toda la artillería pesada ideológica contra el socialismo, concretamente la concepción integral y el papel regulador del Estado. De ahí que el siempre problemático equilibrio entre el dinamismo económico y la estabilidad social no puedan ser asegurados por un Estado fuerte sino por la armónica colaboración de las diferentes clases y grupos sociales en busca del interés colectivo. La cuestión del pluralismo como sinónimo de caos e inestabilidad supone un verdadero tabú para el pensamiento conservador alemán que esconde los peores recuerdos de la experiencia de la República de Weimar. En este sentido, una pista de gran valor es que la idea de «sociedad formada», en participio pasado, contrasta con la retórica política de la era de Weimar, cuando se hablaba de «la sociedad que viene» o «el pueblo naciendo» (das werdende Volk), como agudamente ha visto Benezra Strote (2017: 264).

Sobre la idea de sociedad formada resulta ilustrativo destacar que fue un eslogan político impulsado por Rüdiger Altmann, consejero de Erhard y alto cargo de la Cámara Alemana de Comercio e Industria, a quien también le debemos una definición todavía más explícita del poder estatal desde la perspectiva ordoliberal: el desarrollo de las sociedades industriales habría llevado al 
Estado a una situación en que este «se ha desparramado en un reguero de funciones», otorgándose «la última palabra en todo lo que tiene que ver con el poder» y comportándose - la comparación es muy plástica- como un «gato castrado que engorda y al que le falta fuerza» (citado en Somma, 2014b: 50).

Frente al caos de la democracia de masas y la intervención estatal, evocaciones de Weimar y el nazismo, la necesidad de un nuevo orden. Para ello, la solución de Eucken (1932: 320) pasa por apelar a un Estado liberal y autoritario al mismo tiempo, capaz de hacerle frente al pluralismo propio de la democracia parlamentaria a través de una tecnocracia cuya instrucción sea obra de «hombres de ciencia» con una «rigurosa formación en teoría económica» capaces de entender «los procesos económicos que existen en una economía capitalista libre, pero que son destruidos por la transformación del estado en un estado económico». No es muy atrevido inferir que Eucken se refiere al propio círculo de economistas y juristas ordoliberales, como tampoco es azaroso que en la segunda nota al pie de página de su texto Eucken incluya como única referencia no económica la obra El guardián de la Constitución, de Carl Schmitt, cuya teoría del Reich como poder neutro buscaba «esconder el contraste de intereses, efectivo y radical, que se expresa en la realidad de los partidos políticos y en la realidad, aún más importante, del conflicto de clases que está dentro» (Herrera, 1994: 219).

La desconfianza en el Estado y los recelos respecto al dirigismo y la planificación no implican, como ya advertimos, un retorno al ingenuo liberalismo clásico. Los ordoliberales comparten con el neoliberalismo una perspectiva filosófica que podríamos denominar constructivista, ya que no depositan su confianza en las meras fuerzas del mercado, dejadas a su propia suerte, las cuales se revelan incapaces de aportar orden a la sociedad. El hecho de que los mecanismos mercantiles per se no puedan desarrollarse autónomamente e imprimir su dinámica a la sociedad conlleva la necesidad de una total reordenación a nivel de política económica y sistema monetario, del mercado de trabajo y salarios, de políticas de competencia, fiscalidad e impuestos, todo ello de la mano de un Estado que aplique intervenciones jurídicas, pero no administrativas. Como el orden social no es espontáneo, el ordoliberalismo debe aportar orden a la sociedad mediante un esfuerzo extra para que la economía no funcione a pesar del Estado, sino gracias a él. Este ímpetu organizador expresa la naturaleza constructiva del ordoliberalismo, al insistir persistentemente en un esfuerzo político y organizativo (de naturaleza jurídica) para darle forma y orden a la sociedad, controlando la interdependencia entre los órdenes económicos, legales y político-sociales. Para conseguirlo, se trata de hallar un modo organizativo capaz de 
hacerse cargo de todos los aspectos, una verdadera política social orgánica, la cual quedaría acuñada por el ordoliberal Alexander Rüstow (1951: 453-459) como Vitalpolitik.

\section{GESELLSCHAFTSPOLITIK Y EL MARCO DE COMPETENCIA PERFECTA}

Para conciliar los distintos órdenes sociales y articular una Vitalpolitik, los ordoliberales conciben la idea de constitución económica (Wirtschafsverfassung), definida como una «decisión general de carácter político sobre cómo la vida económica de la nación debe ser estructurada» (Böhm, Eucken y GrossmanDoerth, 1989 [1936]: 24). Esta cosmovisión se cifra en el denominado «imperativo de Friburgo» (Rieter y Schmolz, 1993), consistente en dictar la institucionalización de unos principios regulatorios (Regulierende Prinzipen), entre los que están el control de los monopolios o las desigualdades sociales, y unos principios constituyentes (Konstituierende Prinzipen), como promover el orden de competencia perfecta, la primacía de la estabilidad de precios, la apertura de los mercados, los derechos fuertes de propiedad privada, la libertad de contrato y responsabilidad de los agentes económicos, así como la regularidad y predictibilidad de la política económica. El objetivo de tales ideas, más científicas que políticas según el ideológico juicio de estos autores, es mantener, fomentar y establecer al mismo tiempo un orden económico libre (freiheitlich) y humanamente aceptable (menschewürdig), objetivo que no podría obtenerse por la economía de mercado per se ni a través de la planificación económica socialista controlada por el Estado.

Ahora bien, si el Estado sufre un repliegue en sus funciones intervencionistas y mecanismos regulatorios, pero no se pone en duda su eficacia y utilidad, ¿en qué consiste específicamente su naturaleza bajo el ordoliberalismo? La intuición ordoliberal es que el modo de acceso para conocer la verdadera lógica del Estado es interpretarlo a través del derecho privado, y la fórmula economía social de mercado resulta fundamental en este sentido. A propósito de esta cuestión, Alessandro Somma (2014a: 13) señala que la combinación de libre mercado y socialidad expresa el núcleo doctrinal del ordoliberalismo, consistente en la creencia en el mercado como el mecanismo óptimo para producir y redistribuir la riqueza, al mismo tiempo que consigue «imponer la competencia a través de la despolitización del poder». Según los principios ordoliberales, la competencia es el mecanismo social e instrumento de gobierno encargado de ordenar, 
controlar y planificar los comportamientos individuales que forman parte del engranaje social. Al Estado le queda reservado el papel de crear las condiciones óptimas de funcionamiento del régimen de competencia. Así las cosas, este movimiento teórico con consecuencias políticas produce una triple reducción: 1) la del orden social al orden económico; 2) la del ciudadano al consumidor; y 3) la de la inclusión social a la inclusión en el mercado (Somma, 2014a: 95-96).

Como resultado, asuntos tan fundamentales como el pluralismo político, la diversidad de intereses entre clases y el conflicto capital-trabajo se reducen para los ordoliberales «distinguiendo entre los intereses de los individuos en tanto que productores y los intereses de los individuos en tanto que consumidores» (Laval y Dardot, 2017: 51), despojando al sujeto político de ciudadanía en sentido integral, ya que ante todo su identidad política es la del consumidor y productor. Los principios constituyentes y regulatorios que dan forma a la arquitectura institucional ordoliberal se revelan entonces como auténticos mecanismos biopolíticos para ordenar, corregir y hacer funcionales las conductas individuales al orden social. Alfred Müller-Armack, padre de la expresión economía social de mercado, explica que «la economía de mercado era llamada "social" porque obedece a las elecciones de los consumidores, porque realiza una democracia de consumo gracias a la competencia, presionando a las empresas y a los asalariados para mejorar la producción» (citado en Laval y Dardot, 2013: 118-119). Res publica y mercado, espacio público y competencia, órdenes cuyas fronteras se desdibujan según la peculiar concepción ordoliberal de la democracia, con su identificación de orden político y económico, y que revela la verdadera preeminencia del mercado sobre el Estado, con capacidad de convocar un plebiscito cotidiano que se nutre del consenso de los ciudadanos-consumidores. El jurista ordoliberal Franz Böhm (1947: 500) lo dice explícitamente: «una economía de mercado libre y competitivo es la expresión más perfecta de la democracia de masas en un grado de perfección que la vida política ni se aproxima a imitar», en la cual el consumidor protagoniza un fenómeno de «voto que se produce a diario, cada hora e incluso cada minuto». El verdadero vínculo entre los individuos y mediación del cuerpo social es la competencia, la cual, como han señalado Laval y Dardot (2013: 122) es «al mismo tiempo, más conforme con la eficacia económica y con las exigencias morales que se pueden esperar del hombre, en la medida que le permite afirmarse como un ser autónomo, libre y responsable de sus actos».

Esta mezcla de individualismo antropológico y fusión del orden político en el económico hasta hacerlos indistinguibles provocan que la figura del ciuda- 
dano y del consumidor sean dos caras de un mismo orden que tiende a la competencia perfecta y cuya propia dinámica debe ser capaz de autorregularse y reproducirse sin la intervención de mecanismos planificadores externos, ya sea la actividad estatal o sean otro tipo de obstáculos de naturaleza ética, social y antropológica. Sobre tales impedimentos, Walter Eucken (1932: 301) afirma que la culpa es de una peculiar «organización de los pueblos alrededor del Estado y la sociedad» que «obstruye seriamente el funcionamiento del mecanismo capitalista, limitando su desarrollo e incluso haciéndolo imposible». Frente a tales obstáculos, el mercado se revela como el espacio por excelencia donde tiene lugar el proceso de formación de subjetividades y que educa, disciplina y dirige a los individuos de acuerdo con el orden de la competencia, hasta tal punto que «cuanto más eficaz es esta política de ordenamiento, menos importante se vuelve la política reguladora del proceso» (Laval y Dardot, 2013: 113). Esta combinación, solo aparentemente paradójica, de atomismo social y dominación colectiva concibe al individuo como un sistema de incentivos y desincentivos cuya conducta se basa en los «automatismos aptos para sincronizar el interés individual y los intereses colectivos». Tal es la verdad de la economía social de mercado y su política social, resumida por Foucault (2004: 166) de una forma brillante: «la Gesellschaftspolitik no pretende anular los efectos antisociales de la competencia, sino los mecanismos anticompetencia que pueden surgir de la sociedad, que pueden surgir en cada caso desde la sociedad».

Antes de terminar esta sección, una precisión de carácter metodológico y epistemológico que ayude a despejar el uso, prácticamente indistinto, de los conceptos neoliberalismo y ordoliberalismo. El neoliberalismo y el ordoliberalismo tienen una raíz común desde el punto de vista de los objetivos político-económicos: ambas doctrinas protagonizan la celebración de dos reuniones donde una constelación de intelectuales (entre ellos, ordoliberales como Alexander Rüstow y Ludwig Erhard) se propuso refundar el liberalismo clásico, cuyos cimientos temblaron en la convulsa década de 1920. Nos referimos al Coloquio Walter Lippmann (1938) y a la fundación de la Sociedad Mont Pèlerin (1947). En ambas reuniones, el objetivo común es revisar las bases doctrinales del viejo neoliberalismo, basado en la ingenua idea del laissez-faire, convertida en dogma e incapaz de captar la naturaleza de la política, la economía y el derecho. Una de las consecuencias fundamentales de estos debates es que el eje de discusión no está tanto en laissez-faire contra intervencionismo, sino un buen intervencionismo (del que el nuevo liberalismo sería abanderado) frente a un mal intervencionismo (representado en aquella época por el keynesianismo y el comunismo de la URSS) en los planos socioeconómicos y jurídicos. 
Esta matriz común impulsaría las trayectorias de políticos e ideólogos ordoliberales y neoliberales. Ahora bien, aunque tanto las diferencias como las semejanzas filosóficas existan, es importante distinguir en el plano del análisis las doctrinas y teorías de la práctica efectiva de las políticas. En este sentido, el auge e implantación global del neoliberalismo a partir de la crisis del compromiso socialdemócrata keynesiano-fordista de los años setenta ha podido ocultar la importancia del ordoliberalismo en el proceso de integración de la UE. Las hibridaciones de ambas políticas a lo largo de las últimas décadas nos permiten pensar que tanto el ordoliberalismo como el neoliberalismo desdibujan considerablemente sus diferencias en la práctica, sin perjuicio de que a nivel teórico o discursivo (como modelo deseable) puedan mantenerse.

En definitiva, cuando se trata de comprender el plano de los efectos prácticos de las políticas, las diferencias entre ordoliberalismo y neoliberalismo anglosajón son poco relevantes, como ha estudiado Francesco Denozza (2019: 327 y ss.). Prueba de ello es que ambos modelos han contribuido a la fisionomía del capitalismo tardío de nuestra época, a saber, la recurrencia de dinámicas de acumulación por desposesión a partir de 1970 mediante las cuales el capitalismo ha sorteado las contradicciones en los modos de producción y reproducción social: la privatización y la mercantilización, la financiarización, la gestión y la manipulación de la crisis, las redistribuciones estatales (Harvey, 2011: 175-180).

\section{EL ORDOLIBERALISMO COMO MATRIZ POLÍTICA, ECONÓMICA Y SOCIAL DE LA UNIÓN EUROPEA}

Algunos autores han insistido en que la larga sombra del ordoliberalismo se proyecta en el incierto proceso de integración europea, erigiéndose como la verdadera «tradición oculta» -o quizás no tanto, como veremos inmediatamente- de la Unión Europea (Dullien y Guérot, 2012; Laval y Dardot, 2013; Biebricher, 2014; Schäfer, 2016; Bonefeld, 2017; Biebricher y Vogelmann, 2017; Cayla, 2019). Aunque la constitución de la Comunidad Europea fue una expresión de intereses macroeconómicos y geopolíticos diversos, la visión ordoliberal de un mercado único competitivo acabó imponiéndose. Laval y Dardot (2013: 258) recuerdan cómo, ya en 1948, cristalizó la idea «ante las instancias de ocupación responsables de la política económica, fomentada al parecer por Ludwig Erhard, de un Consejo Económico dominado por los ordoliberales». En sus orígenes, la orientación del continente europeo en una dirección ordoliberal será 
tarea de Ludwig Erhard y su asesor Armand Müller-Armack, quienes inscribieron los principios del nuevo liberalismo en los Tratados de Roma de 1957 (Moss, 2005: 13), con su orientación hacia un «mercado interior caracterizado por la supresión, entre los Estados miembros, de los obstáculos a la libre circulación de mercancías, personas, servicios y capitales» en posición de garantizar «que la competencia no será falseada en el mercado interior», para lo que sería una condición «la aproximación de las legislaciones nacionales en la medida necesaria para el funcionamiento del mercado común» (art. 3). Tan liberales principios, ante todo los de la libertad de comercio y la libertad de capitales, decretan «prohibidas las restricciones a la libertad de establecimiento de los nacionales de un Estado miembro en el territorio de otro Estado miembro», lo que se extiende a «agencias, sucursales o filiales», eliminando las barreras «cuyo mantenimiento suponga un obstáculo para la libertad de establecimiento» (art. 43). Todo ello guiado por el mantra monetarista ordoliberal de una política macroeconómica antiinflacionista destinada al «logro de un alto grado de estabilidad de precios» (art. 121).

Si en el embrión de la futura Unión Europea ya estaban inscritos estos fundamentos, las décadas posteriores vieron multiplicar la influencia y adhesión a los principios ordoliberales por parte de las élites europeas. El triunfo de un espacio único de competencia sin obstáculos precedió a la introducción, en 1979, del Sistema Monetario Europeo y la unidad monetaria europea, una unidad de cuentas cuyo valor consistió en la media ponderada del valor de las monedas de los países miembros, las cuales debían someterse a la restricción de no oscilar más allá de unos márgenes prestablecidos y definidos. En caso de que un país miembro se aproximase a estos márgenes, sin capacidad de devaluaciones ni modificación en los tipos de cambios, se vería obligado a adoptar medidas de reformas e intervenciones acordadas por los países miembros. El Acta Única Europea de 1986 profundizó en la misma dirección para acabar con los importantes obstáculos a la libre circulación adquiriendo así la Unión nuevas competencias en política monetaria y cohesión económica, con el objetivo de culminar un mercado y una moneda únicos. La multiplicación y sofisticación de mecanismos ordoliberales en el proceso de integración europea se reveló como un dispositivo eficaz para limitar e incluso impedir cualquier posibilidad de llevar a cabo políticas de tipo keynesianas, destinadas al aumento de la demanda interna o al pleno empleo, incluso las que fueran dirigidas exclusivamente a enfrentarse a los ciclos económicos negativos. De una forma cada vez más acusada, el marco económico se iba estrechando considerablemente, limitando la capacidad de 
maniobra de los Estados miembros y desechando de antemano cualquier aproximación económica heterodoxa o simplemente incompatible con el modo ordoliberal de comprender «el régimen de competencia perfecto» al que tendía la Unión Europea.

La imposibilidad de llevar a cabo políticas progresistas bajo la «jaula ordoliberal» tuvo su verdadera prueba de fuego en Francia, bajo el gobierno del socialista François Mitterand. ${ }^{3}$ En 1981 el político francés fue elegido presidente, respaldado por un programa electoral de inspiración comunista basado en el aumento del gasto público, nacionalizaciones y políticas de creación de empleo, concebido como un auténtico desafío para las élites alemanas y, por lo mismo, una amenaza para el desarrollo de la integración europea. Dos años más tarde llega el punto de inflexión: en la primavera de 1983 Mitterand diseña un plan para abandonar el Mecanismo Europeo de Cambio y así poder levantar las barreras proteccionistas que le permitieran llevar a cabo su programa de reindustrialización. Las facciones eurófilas de su gabinete, encabezadas por el ministro de Economía y Finanzas Jacques Delors, lo impiden. Desde ese momento y tras las presiones diplomáticas, políticas y monetarias alemanas, el gobierno socialista da un giro a la austeridad con la puesta en marcha de la desregulación financiera, los recortes en el gasto y presupuesto estatales, comercialización de servicios públicos, privatizaciones parciales y el consentimiento de una situación de debilidad de la moneda nacional frente al marco alemán. El 19 de febrero de 1983, Jacques Attali (1993), asesor económico del presidente, anotará en su cuaderno las siguientes palabras de Mitterand: «Estoy dividido entre dos ambiciones: la construcción de Europa y la justicia social».

Con el Tratado de Maastricht (1992), la disyuntiva entre más justicia social o más Europa se hizo finalmente evidente. Perry Anderson (2012: 125) recuerda que «la adhesión a la Unión Europea en 1993-1994 privó al Estado de muchas de las herramientas que anteriormente había mantenido para combatir el desempleo y hacer avanzar el salario social». También Anderson (2012: 267-269) ha recogido varias de las líneas fundamentales a nivel de política monetaria que el ordoliberalismo inscribe en la UE resultante de Maastricht. En primer lugar,

\footnotetext{
Johann Michel (2008) interpreta el giro a la austeridad de Mitterand como un punto de inflexión en la implantación del neoliberalismo en Francia. La consecuencia, el sacrificio de los dos principales consensos de posguerra: el objetivo de disminuir las desigualdades económicas y sociales, por una parte, y evitar a toda costa privatizar servicios públicos, por otra. Una descripción breve pero precisa de estos acontecimientos puede encontrarse en el trabajo de McNamara (1998). Para el trasfondo y las consecuencias económicas del giro a la austeridad de Mitterand véase Sachs y Wyplosz (1986). A Garrigou (2017) le debemos uno de los mejores análisis de la situación y destino de la izquierda francesa entre 1981 y 1986.
} 
la obsesión con la estabilidad de precios en un régimen de competencia «perfecta» que prohíbe cualquier «ajuste de la coyuntura con ayuda de los instrumentos de la moneda y del presupuesto, o sea, de la policy mix de inspiración keynesiana». Además, la Comisión Europea encaja con el papel de un gobierno liberal pero autoritario tan querido por los ordoliberales, ya que su función consiste «en dar a una instancia "técnica", situada por encima de los gobiernos, el poder de imponer "las reglas del juego"», de modo que las autoridades europeas, como árbitros y vigilantes del orden económico, controlan la economía en todos los niveles, constituyendo una "política industrial" que es al mismo tiempo una "no-política", ya que se determina de acuerdo con reglas y no de acuerdo con fines», una política del marco que se inspira en los principios constituyentes y reguladores del ordoliberalismo, afirmando «el derecho de la competencia sobre toda otra consideración, en particular social o política». Para el historiador británico, la fidelidad de la Comisión a la doctrina ordoliberal se hace especialmente patente en la cuestión de los "servicios económicos de interés general", que deben estar sometidos también a la regla suprema de la competencia», un derecho que prima sobre los demás y que expresa la visión ordoliberal del individuo como consumidor y productor: «Europa se ajusta a este ideal del "consumidor rey" que siempre debe poder elegir su empresa de servicios».

\section{INTEGRACIÓN EUROPEA Y NEOLIBERALISMO DISCIPLINARIO: EL NUEVO CONSTITUCIONALISMO}

La matriz ordoliberal que inspira la política macroeconómica y social de la Unión Europea se ha impuesto a través de un proceso que podríamos denominar neoliberalismo disciplinario y el cual funciona a través del derecho comunitario y las políticas macroeconómicas de shock. A lo largo de la integración europea se ha tejido una red jurídico-política de tratados, instituciones, mecanismos y reformas en la que la soberanía de cada Estado miembro resulta gravemente debilitada. La fórmula «democracia acorde a los mercados» (marktkonformen Demokratie), acuñada hace unos años por la canciller alemana Angela Merkel, da buena cuenta del vaciado democrático y la sumisión política a los mercados, deviniendo así patrón de la UE un motivo constante de la literatura ordoliberal, a saber, la reticencia a la democracia de masas y la regulación política de la economía, considerados auténticos obstáculos e impedimentos para el desarrollo de la competencia. 
Maastricht, 1992, de nuevo como fecha clave si queremos hablar del neoliberalismo como modo de regulación de la UE. Leemos en el Tratado que la UE y los Estados miembros deben actuar de acuerdo con los principios de «una economía de mercado abierta y de libre competencia» (art. 3A y art. 102A), donde el «Consejo, basándose en informes presentados por la Comisión, supervisará la evolución económica de cada uno de los Estados miembros [...] así como la coherencia de las políticas económicas» (art. 103, cursiva propia). Para ello, el Banco Central Europeo «podrá presentar dictámenes a las instituciones u organismos comunitarios o a las autoridades nacionales pertinentes acerca de materias que pertenezcan al ámbito de sus competencias» (art. 104C). El adecuado seguimiento de los principios comunitarios cuenta, además, con un guardián del derecho europeo con un poder tal que «si el Tribunal de Justicia de la Unión Europea declarare que un Estado miembro ha incumplido una de las obligaciones que le incumben en virtud de los Tratados, dicho Estado estará obligado a adoptar las medidas necesarias para la ejecución de la sentencia del Tribunal» (art. 260).

La tendencia a un orden de competencia perfecto no puede completarse sin aquello que los ordoliberales denominaban «constitución económica», a saber, la constitucionalización — de manera más o menos explícita- del derecho privado como marco amplio de la política económica. «Construyendo Europa, construyendo instituciones» es el título de un discurso pronunciado por el expresidente del BCE Jean-Claude Trichet (2011) en el que exigía para las instituciones europeas una capacidad de actuación «más profunda y autoritaria». En esta línea, el expresidente de la Comisión Europea Jean-Claude Juncker (citado en Hewitt, 2015) afirmaba lo siguiente a propósito de la crisis griega: «no puede haber elección democrática en contra de los tratados europeos». Estas expresiones dan buena cuenta de la superioridad de cualquier ley europea y el modo - autoritario si así se exige- en que prevalece sobre la regulación nacional. De hecho, el Tribunal de Justicia Europeo ha ido ampliando cada vez más sus dominios hasta legislar, por ejemplo, sobre materias laborales que afectan a cada Estado miembro. El TJE, junto a la Comisión como poder ejecutivo fuerte, hacen que la UE esté en posición de romper la capacidad regulativa de los Estados que la componen aunque ello implique una contradicción con su derecho nacional. ${ }^{4}$

\footnotetext{
El marco general de estos fenómenos es lo que Gill y Cutler (2014) han denominado «New Constitutionalism», cuyo objetivo es desvincular las políticas económicas del control democrático y social mediante su atribución a marcos jurídicos de carácter transnacionales e incluso globales. Aplicado a nuestro caso, Monica Claes (2007) ha denominado a este tipo de fenómenos la «europeización de las constituciones nacionales». Ya en una sentencia de 1970 emitida por el Tribunal de Justicia leemos, como una siniestra profecía
} 
Cafruny y Ryner (2003: 65-66) han reconocido estos fenómenos como elementos del «nuevo constitucionalismo» que busca reconfigurar el Estado de acuerdo a los principios de la «economía social de mercado» como una institución ajena a cualquier tipo de rendición de cuentas popular y democrática, siendo uno de sus objetivos principales «prevenir que futuros gobiernos deshagan el compromiso con el patrón disciplinario de acumulación neoliberal». De este modo, se estrecha significativamente el marco de la regulación y acción política dentro de una sociedad capitalista, al mismo tiempo que se limita lo que los partidos políticos podrán hacer en un futuro.

Este conjunto de normas disciplinarias conjuran al «fantasma de un derecho "autorreferencial", que solo sería alimentado por su propia lógica interna, una lógica estrictamente técnica», como ha afirmado la politóloga belga Corinne Gobin (2013). Este derecho autorreferencial compuesto por mecanismos que actúan de un modo automático, al modo de intervenciones puntuales para mantener el orden de la competencia, alcanza su mayor grado de sofisticación en el llamado Semestre Europeo, un procedimiento de vigilancia, mes a mes, a través del cual el Consejo Europeo elabora las líneas de política económica que utilizan los Estados miembros («reciben asesoramiento»y «orientación», según el lenguaje de la eurozona) para presentar sus programas nacionales de reformas y programas de estabilidad que deben ser evaluados a nivel europeo. Estos procesos de «disciplinamiento» suponen la completa inscripción institucional de principios económicos ordoliberales. De ahí que Alessandro Somma (2018: 121)

\footnotetext{
de lo que sucederá décadas más tarde, «que la alegación de violaciones de los derechos fundamentales, tal como están formulados por la Constitución de un Estado miembro, o de los principios de una estructura constitucional nacional no puede afectar a la validez de un acto de la Comunidad o a su efecto en el territorio de dicho Estado». El Tratado sobre Estabilidad, Coordinación y Gobernanza en la Unión Económica y Monetaria Europea surge en plena crisis de la eurozona como una versión más rigorista del Pacto de Estabilidad y Crecimiento, al imponer un conjunto de reglas, denominadas «reglas de oro», orientadas a imponer sanciones automáticas a los países que no cumplan los parámetros relativos a mantener un déficit del $3 \%$ y un ratio de deuda del $60 \%$ respecto al PIB. El caso italiano ha sido estudiado por Barra Caracciolo (2013) en un libro de elocuente título: Euro y (¿o?) democracia constitucional. La convivencia imposible entre constitución y tratados europeos. Su autor ha señalado en otra obra cómo «siguiendo la política económica y fiscal dictada por la adhesión al euro, la Constitución resulta "integralmente subvertida” (Barra Caracciolo, 2015). Habermas ha hablado del riesgo de que la Unión Europea termine por convertirse en una «máscara constitucional de los mercados» (Canfora y Zagrebelsky, 2015: 72). Según recuerda Giacché (2015), en Portugal se presentó un recurso al Tribunal Constitucional que provocó una declaración en el 2013 sobre el carácter ilegítimo de las medidas de austeridad previstas por el memorándum de austeridad impuesto a su gobierno. El catedrático de Derecho Administrativo Ponce Solé (2015) ha estudiado este caso aportando algunas reflexiones de interés para la situación española. El trabajo más solvente sobre la colisión entre la «regla de oro» de la estabilidad presupuestaria y las constituciones nacionales de los Estados miembros, con interesantes reflexiones sobre la legitimidad y futuro de la integración europea, es de Adams, Fabbrini y Larouche (2014).
} 
haya afirmado la centralidad de «la construcción europea como un vínculo centrado en el derecho, de algún modo llamado a suplir la ausencia de legitimidad popular». De nuevo la posición ordoliberal: desconfianza en la democracia social y económica y necesidad de principios jurídicos que aporten orden a la sociedad al margen del pluralismo político. Frente al entramado de tratados, pactos y regulaciones europeos, los Estados miembros se convierten en entes pasivos en manos de una estructura supranacional que adquiere la forma de un proto-Estado autoritario. Wolfgang Streeck (2016: 116) ha identificado un doble movimiento a través del cual la política estatal queda sujeta a los principios de la razón económica, por un lado, la «autosujeción unilateral de la voluntad, encarnada en "techos de deuda" de anclaje constitucional» y, por otro, la «sujeción externa a través de tratados internacionales o de compromisos jurídicos europeos». De esta forma, se constitucionaliza la racionalidad neoliberal como patrón de conducta de cada Estado miembro, por lo que no es de extrañar que algunos autores (Barba, D'Angelillo, Lehndorff, Paggi y Somma, 2016: 19) hayan comentado que «Maastricht, en realidad, no es solo una moneda única, es también una cultura, una concepción del mundo, una propuesta de "civilización"».

\section{CONCLUSIÓN}

Este recorrido por algunos de los fundamentos del ordoliberalismo y su difusión en el proceso de integración europea espera haber contribuido a una literatura escasa en el ámbito de la filosofía política hispánica. Creemos que una investigación sobre los motivos ordoliberales — ajustes en la dimensión y funciones del Estado, la racionalidad económica y el orden de competencia- puede aportar alguna luz para comprender las ideas políticas y macroeconómicas dominantes en el ámbito europeo. A su vez, una genealogía y diagnóstico de la UE en clave ordoliberal, la cual no hemos podido más que esbozar, nos ofrece algunas respuestas para descifrar la naturaleza del nuevo constitucionalismo disciplinario en el corazón de Europa por el que filósofos como Habermas han hablado de retorno al «nacionalismo del marco alemán» (Deutsche-mark nationalism), en alusión a una «cultura de procedimientos destinada a neutralizar las decisiones políticas en nombre de un virtuoso gobierno tecnocrático» (Lapavitsas, 2012: xvi).

La «civilización Maastricht» nos coloca frente a una involución política, social y antropológica provocada por la implantación del ordoliberalismo, una 
doctrina alejada de la conciliación de intereses comunes de los países que componen la UE y basada, más bien, en un nuevo constitucionalismo disciplinario cuyo objetivo es desvincular las políticas nacionales del control democrático y social mediante su atribución a marcos jurídicos de carácter transnacional. Nos preguntamos si este desgarro ético ha pagado el precio de incubar una forma contradictoria, multiforme y oscura del retorno de la lucha de clases en el siglo XXI: el populismo como desafío a una sociedad posdemocrática. Una reciente tragedia griega puede resultar esclarecedora: el 5 de julio de 2015 Grecia vota en referéndum no a las condiciones del rescate de las crisis propuestas por la Unión Europea con casi un $62 \%$ de los votos. Menos de una semana después, el gobierno encabezado por el izquierdista Alexis Tsipras acepta el plan de austeridad que el pueblo griego rechazó en el referéndum, dando implícitamente una respuesta afirmativa a los famosos versos de Bertolt Brecht: «¿No sería más simple / En ese caso para el gobierno / Disolver el pueblo / Y elegir otro?». Al fin y al cabo, para el ordoliberalismo la democracia no es más que un obstáculo para la competencia perfecta y, como nos recuerdan las palabras del expresidente del BCE Mario Draghi (2012), «el Banco Central Europeo está listo para hacer lo que sea necesario con el objetivo de preservar el euro. Y creedme, será suficiente».5 Fue suficiente.

\section{BIBLIOGRAFÍA}

Adams, Maurice, Fabbrini, Federico y Larouche, Pierre (2014). The constitutionalization of European budgetary constraints. London: Bloomsbury Publishing.

Anderson, Perry (2012). El nuevo viejo mundo. Madrid: Akal.

Attali, Jacques (1993). Verbatim I. Paris: Fayard.

Barba, Aldo, D'Angelillo, Massimo, Lehndorff, Steffen, Paggi, Leonardo y Somma, Alessandro (2016). Rottamare Maastricht.

\footnotetext{
En marzo de 2015 el BCE empieza a comprar bonos en el mercado, inyectando 1,1 billones de euros para disminuir la presión sobre las primas de riesgo. Esta operación, denominada Quantitative Easing, es considerada por el mismo BCE como una de sus «medidas de política económica no convencionales» (a pesar de que la Federal Reserve estadounidense y el Bank of Japan lo hicieron años antes). Solo con el ya mítico anuncio de Mario Draghi los mercados internacionales reaccionaron - a veces en cuestión de horas - de un modo espectacular: la disminución de las primas de riesgo y el mejor ascenso en dos ańos del Ibex 35. Otra de las operaciones anunciadas por Draghi fueron las Outright Monetary Transactions, gracias a la cual el BCE podría comprar deuda pública de países como España e Italia. Nunca se llevó a cabo.
} 
Questione tedesca, Brexit e crisi della democrazia in Europa. Roma: DeriveApprodi.

Barra Caracciolo, Luciano (2013). Euro e (o?) democrazia costituzionale: La convivenza impossibile tra Costituzione e trattati europei. Roma: Dike giuridica.

Barra Caracciolo, Luciano (2015). La Costituzione nella palude. Indagine su trattati al di sotto di ogni sospetto. Reggio Emilia: Imprimatur.

Biebricher, Thomas (2014). The return of ordoliberalism in Europe: notes on a research agenda. Rivista quadrimestrale on-line: www. $i$ lex.it, 21, 1-24.

Biebricher, Thomas y Vogelmann, Frieder (2017). The birth of austerity: German ordoliberalism and contemporary neoliberalism. Lanham: Rowman \& Littlefield International Ltd.

Böhm, Franz (1947). Kartellauflösung und Konzernentflechtung Spezialistenaufgabe uber Schicksalsfrage? Süddeutsche JuristenZeitung, 2(9), 495-506.

Böhm, Franz, Eucken, Walter y Grossmann-Doerth, Hans (1936/1989). The Ordo Manifesto of 1936. En Peacock, Alan y Willgerodt, Hans (Eds). Germany's Social Market Economy: Origins and Evolution (15-26). London: Palgrave Macmillan, 1989.

Bonefeld, Werner (2017). Authoritarian liberalism: From Schmitt via ordoliberalism to the Euro. Critical sociology, 43(4-5), 747-761.

Cafruny, Alan W. y Ryner, Magnus (2003). A Ruined Fortress? Neoliberal Hegemony and Transformation in Europe. Lanham: Rowman \& Littlefield Publishers.

Canfora, Luciano y Zagrebelsky, Gustavo (2015). La maschera democratica dell'oligarchia. Roma: Laterza.

Cayla, David (2019). The Rise of Populist Movements in Europe: A Response to European Ordoliberalism? Journal of Economic Issues, $53(2), 355-362$.

Claes, Monica (2007). The Europeanisation of national constitutions in the constitutionalisation of Europe: Some observations against the 
background of the constitutional experience of the EU-15. Croatian yearbook of European law \& policy, 3(3), 1-38.

Denozza, Francesco (2019). Spettri del mitico «ordo»: diritto e mercato nel neoliberalismo, Moneta e Credito, $72(288), 327-348$.

Dullien, Sebastian y Guérot, Ulrike (2012). The long shadow of ordoliberalism: Germany's approach to the euro crisis. London: European Council on Foreign Relations (ECFR).

Erhard, Ludwig (1982 [1965]). Our Social Model: an Integrated Society. En Wünsche, Horst Friedrich (Ed.). Standard Texts on the Social Market Economy (63-80). Stuttgart: Fischer.

Eucken, Walter (1932). Staatliche Strukturwandlungen und die Krisis des Kapitalismus. Weltwirtschaftliches Archiv, 36, 297-321.

Foucault, Michel (2004). Naissance de la biopolitique. Cours au Collége de France. 1978-1979. Paris: Seuil/Gallimard.

Garrigou, Alain (2017). François Mitterrand et la gauche au pouvoir (1981-1986). En Garrigou, Alain (Ed.). La politique en France: De 1940 à nos jours (265-289). Paris: La Découverte.

Giacché, Vladimiro (2015). Costituzione italiana contro Trattati Europei. Il conflitto inevitabile. Reggio Emilia: Imprimatur.

Gill, Stephen y Cutler, Claire A. (2014). New Constitutionalism and World Order. Cambridge: Cambridge University Press.

Gobin, Corinne (2013). L'Union européenne et la nouvelle gouvernance économique: un système politique contre l'Etat démocratique. Pyramides. Revue du Centre d'études et de recherches en administration publique, 25, 155-180.

Habermas, Jürgen (1975). Perfiles filosófico-políticos. Madrid: Taurus.

Harvey, David (2011). Breve historia del neoliberalismo. Madrid: Akal.

Herrera, Carlos Miguel (1994). La polémica Schmitt-Kelsen sobre el guardián de la Constitución. Revista de Estudios Políticos, 86, 195228.

Hewitt, Gavin (2015). Greece: The dangerous game. Recuperado de: https://www.bbc.com/news/world-europe-31082656 [Consultado el 2 de junio de 2020]. 
Lapavitsas, Costas (2012). Crisis in the Eurozone. London: Verso. Laval, Christian y Dardot, Pierre (2013). La nueva razón del mundo. Ensayo sobre la sociedad neoliberal. Barcelona: Gedisa.

Laval, Christian y Dardot, Pierre (2017). La pesadilla que no acaba nunca. Barcelona: Gedisa.

McNamara, Kathleen R. (1998). The Currency of Ideas: Monetary Politics and the European Union. Ithaca: Cornell University Press.

Michel, Johann (2008). Peut-on parler d'un tournant néo-libéral en France? Recuperado de: http://www.sens-public.org/articles/577 [Consultado el 2 de junio de 2020].

Moss, Bernard H. (2005). Monetary Union in Crisis. The European Union as Neo-liberal Construction. London: Palgrave Macmillan.

Ponce Solé, Juli (2015). El estado social y democrático de derecho ante la austeridad y los recortes sociales: La jurisprudencia del tribunal constitucional portugués y su interés para el caso español. Revista de Derecho constitucional europeo, 23, 14.

Rieter, Heinz y Schmolz, Matthias (1993). The ideas of German Ordoliberalism 1938-45: pointing the way to a new economic order. Journal of the History of Economic Thought, 1(1), 87-114.

Rüstow, Alexander (1951). Sozialpolitik oder Vitalpolitik. Mitteilungen der Industrie- und Handelskammer Dortmund, 11, 453-459.

Rüstow, Alexander (2017 [1932]). State Policy and the Necessary Conditions for Economic Liberalism. En Biebricher, Thomas y Vogelmann, Frieder (Eds.). The birth of austerity: German ordoliberalism and contemporary neoliberalism (143-149). Lanham: Rowman \& Littlefield International Ltd.

Sachs, Jeffrey y Wyplosz, Charles (1986). The Economic Consequences of President Mitterrand. Economic Policy, 1(2), 262-322.

Schäfer, David (2016). A banking union of ideas? The impact of ordoliberalism and the vicious circle on the EU banking union. JCMS: Journal of Common Market Studies, 54(4), 961-980.

Somma, Alessandro (2014a). La dittatura dello spread. Germania, Europa e crisi del debito. Roma: DeriveApprodi. 
Somma, Alessandro (2014b). La Germania e L'economia sociale di mercato (1. Da Weimar a Helmut Schmidt). Torino: Centro di Ricerca e Documentazione Luigi Einaudi.

Somma, Alessandro (2018). Sovranismi. Stato, popolo e conflitto sociale. Roma: DeriveApprodi.

Streeck, Wolfgang (2016). Comprando tiempo. La crisis pospuesta del capitalismo democrático. Buenos Aires y Madrid: Katz.

Strote, Noah Benezra (2017). Lions and Lambs: Conflict in Weimar and the Creation of Post-Nazi Germany. New Haven: Yale University Press.

Thompson, Antonio (2010). Men in German Uniform: POWs in America during World War II. Knoxville: University of Tennessee Press.

Tratado de Maastricht o Tratado de la Unión Europea (Tratado UE) (firma: 7.2.1992; entrada en vigor: 1.11.1993). Recuperado de: http://data.europa.eu/eli/treaty/teu/sign [Consultado el 2 de junio de 2020$]$.

Tratados de Roma (firma: 25.3.1957; entrada en vigor: 1.1.1958). Recuperado de: http://data.europa.eu/eli/treaty/teec/sign [Consultado el 2 de junio de 2020].

Tribunal de Justicia de la Unión Europea (1970). Internationale Handelsgesellschaft mbH v Einfuhr- und Vorratsstelle für Getreide und Futtermittel. Recuperado de: https://eur-lex.europa.eu/legalcontent/ES/TXT/HTML/?uri=CELEX:6197oCJoo11\&from=ES [Consultado el 2 de junio de 2020].

Trichet, Jean-Claude (2011). Construyendo Europa, construyendo instituciones. Recuperado de: https://www.ecb.europa.eu/press/key/date/2011/html/sp1106oz.en. html [Consultado el 2 de junio de 2020]. 